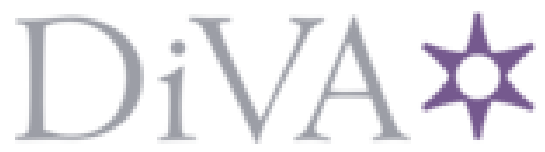

http://www.diva-portal.org

This is the published version of a paper presented at CHI Conference on Human Factors in Computing Systems (CHI'21).

Citation for the original published paper:

Tennent, P., Höök, K., Benford, S., Tsaknaki, V., Ståhl, A. et al. (2021)

Articulating Soma Experiences using Trajectories

In: ACM Press (ed.), CHI Conference on Human Factors in Computing Systems (CHI

'21), May 8-13, 2021, Yokohama, Japan. (pp. 1-16). New York: ACM Press

https://doi.org/https: //10.1145/3411764.3445482

N.B. When citing this work, cite the original published paper.

Permanent link to this version:

http://urn.kb.se/resolve?urn=urn:nbn:se:kth:diva-294582 


\section{Articulating Soma Experiences using Trajectories}

\author{
Paul Tennent \\ paul.tennent@nottingham.ac.uk \\ Mixed Reality Lab, The University of \\ Nottingham \\ Nottingham, UK \\ Vasiliki Tsaknaki \\ vats@itu.dk \\ Digital Design Department, IT \\ University of Copenhagen \\ Copenhagen, Denmark

\section{Charles Windlin \\ windlin@kth.se} \\ Media Technology and Interaction \\ Design, Royal Institute of Technology \\ Stockholm, Sweden

\section{Christine Li} \\ christine.li@nottingham.ac.uk \\ Mixed Reality Lab, The University of \\ Nottingham \\ Nottingham, UK
}

Kristina Höök

khook@kth.se

Media Technology and Interaction

Design, Royal Institute of Technology

Stockholm, Sweden

\author{
Anna Ståhl \\ anna.stahl@ri.se \\ RISE - Research Institute of Sweden \\ Kista, Sweden
}

Pedro Sanches

sanches@kth.se

Media Technology and Interaction

Design, Royal Institute of Technology

Stockholm, Sweden

Juan Martinez Avila

juan.martinez-

avila@nottingham.ac.uk

Mixed Reality Lab, The University of Nottingham

Nottingham, UK

\author{
Steve Benford \\ steve.benford@nottingham.ac.uk \\ Mixed Reality Lab, The University of \\ Nottingham \\ Nottingham, UK \\ Claudia Daudén Roquet \\ c.daudenroquet1@lancaster.ac.uk \\ Lancaster University \\ Lancaster, UK \\ Joseph Marshall \\ joe.marshall@nottingham.ac.uk \\ Mixed Reality Lab, The University of \\ Nottingham \\ Nottingham, UK \\ Miquel Alfaras \\ miquel.alfaras@uji.es \\ Universitat Jaume I \\ Castelló de la Plana, Spain \\ Plux S.A. \\ Lisbon, Portugal
}

\author{
Muhammad Umair \\ m.umair7@lancaster.ac.uk \\ Lancaster University \\ Lancaster, UK
}

Feng Zhou

pszfz@exmail.nottingham.ac.uk

Mixed Reality Lab, The University of

Nottingham

Nottingham, UK

\begin{abstract}
In this paper, we reflect on the applicability of the concept of trajectories to soma design. Soma design is a first-person design method which considers users' subjective somatic or bodily experiences of a design. Due to bodily changes over time, soma experiences are inherently temporal. Current instruments for articulating soma experiences lack the power to express the effects of experiences on the body over time. To address this, we turn to trajectories, a well-known concept in the HCI community, as a way of mapping this aspect of soma experience. By showing trajectories through a range of dimensions, we can articulate individual experiences and differences in those experiences. Through analysis of a set of

Permission to make digital or hard copies of all or part of this work for personal or classroom use is granted without fee provided that copies are not made or distributed for profit or commercial advantage and that copies bear this notice and the full citation on the first page. Copyrights for components of this work owned by others than ACM must be honored. Abstracting with credit is permitted. To copy otherwise, or republish, to post on servers or to redistribute to lists, requires prior specific permission and/or a

fee. Request permissions from permissions@acm.org.

CHI '21, May 8-13, 2021, Yokohama, Japan

(C) 2021 Association for Computing Machinery.

ACM ISBN 978-1-4503-8096-6/21/05 ..\$15.00

https://doi.org/10.1145/3411764.3445482
\end{abstract}

soma experience designs and a set of temporal dimensions within the experiences, this paper demonstrates how trajectories can provide a practical conceptual framing for articulating the temporal complexity of soma designs.

\section{CCS CONCEPTS}

- Human-centered computing $\rightarrow$ Interaction design process and methods.

\section{KEYWORDS}

Soma Design, Trajectories, Somaesthetics

\section{ACM Reference Format:}

Paul Tennent, Kristina Höök, Steve Benford, Vasiliki Tsaknaki, Anna Ståhl, Claudia Daudén Roquet, Charles Windlin, Pedro Sanches, Joseph Marshall, Christine Li, Juan Martinez Avila, Miquel Alfaras, Muhammad Umair, and Feng Zhou. 2021. Articulating Soma Experiences using Trajectories. In CHI Conference on Human Factors in Computing Systems (CHI '21), May 8-13, 2021, Yokohama, Japan. ACM, New York, NY, USA, 16 pages. https: //doi.org/10.1145/3411764.3445482 


\section{INTRODUCTION}

Soma design as a holistic method of interaction design has been steadily gaining traction within the HCI community, particularly amongst those who create kinaesthetically introspective, bodily or sensational experiences [38, 39, 45, 61, 67]. One challenge associated with designing such experiences is that of articulation; it is well known that they are difficult to document, or indeed to describe because they are inherently 'felt'. Approaches to articulation, such as body maps [50], capture a snapshot (or series of snapshots) of bodily sensation. While such representations do serve as an excellent aide-memoire for discussion, they lack the ability to articulate the complexity of somaesthetic journeys and are often difficult to re-interpret after the event, or compare between participants. In this paper we recognise that soma experiences are not fixed points in time. One's arm is not fifteen percent uncomfortable for a five minute experience - sensations change over time. A somaesthetic experience is a journey of complex, nuanced, changing sensations and feelings. We suggest that an articulation which takes this temporal complexity into account is necessary.

Given its holistic perspective, 'soma experience' is not something that can be readily reduced to values or discrete sets of labels. What does it mean to have a high value for one's soma experience? Labels like 'happy' or 'sad' do not capture the subjective, complex nature of the soma. And yet, as soma designers, we need some way of deconstructing soma experiences in order to reflect, analyse and ultimately redesign them. One potentially applicable concept in $\mathrm{HCI}$ is that of trajectories [10], conceived as a way of expressing user journeys through the space, time, roles and interfaces that constitute mixed reality experiences. But what might soma trajectories pass through? In what ways can we usefully express the design space of somatic experience that could then envisage soma trajectories? In what follows, we analyse several soma-designed experiences through the lenses of three 'somaesthetic dimensions' that between them provide a space for uncovering somaesthetic trajectories:

- comfortable<-> uncomfortable

- familiar $<->$ strange

- inside<->outside

We discuss each of these in detail, then use them to draw soma trajectories for each of our experiences. We identified these dimensions, after extensive discussion, as a rich set of somaesthetic characteristics, recognising that they are in no way an exhaustive list, but may be common to many types of soma experience. We use them to show how applying the concept of trajectories to a somaesthetic dimension serves as an analytical tool by which to expand our somaesthetic appreciation of an experience, and helps to support the articulation of our complex, first person, highly subjective relationships with that experience. Following this, we consider the interconnectedness of the dimensions, how movement - whether unintentional or by intervention - in one often affects another. Finally, we discuss the applicability of the concept of soma trajectories as a complementary tool for articulating soma experiences alongside existing tools such as body maps [50], then discuss the inclusion of the concepts from the wider trajectories framework: canonical, participant and historical trajectories, and how soma trajectories may be applied in each of these instances.
Soma trajectories may serve as a powerful concept in soma design, providing a common language through which to discuss experiences: prior to creating them, in the moment with individual participants, and later as a reflective activity across a whole experience with multiple users.

\section{RELATED WORK}

\subsection{Soma Design}

Soma design has its roots in the somaesthetic project proposed by philosopher Professor Richard Shusterman [72]. Somaesthetics combines the term 'soma' with 'aesthetics'. The concept of 'soma' is predicated on the interconnectedness of mind, body, emotion and social engagement, considering all to be inseparable aspects that together form an embodied, holistic subjectivity [73]. Aesthetics here refers to the ways in which we perceive and interact with the world around us. Shusterman draws on Dewey's 1934 argument [43] that aesthetics are not simply a property of an object, but rather a product of active engagement and experience, expanding it to include not just the unique, romantic and beautiful, but also the everyday, ordinary or even disturbing aspects of our experiences. Shusterman posits somaesthetics as the critical study of appreciative perception.

Where soma design particularly draws on the somaesthetic project is in the recognition that somaesthetic appreciation is an active skill which can be developed and trained [41]. Applying a soma design process involves taking a first-person approach to design, engaging ones' somaesthetic appreciation of what one is doing - as Höök puts it, "stop talking-start feeling" [ibid]. There is an inherent recognition of the individuality of each person rather than a shared expectation of experience - which allows for the inclusion of our own individual experience, drawing parallels with Heidegger's hermeneutic circle [36] which recognises that experience for an individual can only be deeply considered in the context of their entire life experience. This first-person approach is methodologically distinct from many other design methods employed in the interaction design field, such as wireframes, creating user personas, or brainstorming with whiteboards, as these are predominantly visual, verbally-oriented processes. Höök frames the difference as "the qualitative shift required, from a predominantly symbolic, language-oriented stance, to an experiential, felt, aesthetic stance permeating the whole design and use cycle" [41].

\subsection{Trajectories}

The idea of 'interactional trajectories' through experiences has emerged from work by Heath and vom Lehn [35], Costello et al. [17], Hornecker and Buur, [40] and others, all of whom recognised that a user's interaction with an experience, interface or exhibit establishes a pattern of interaction which then shapes the way others may interact with the same material. As the idea gained traction in HCI, Benford et al. [10] refined this into the trajectories framework that Höök and Löwgren later referred to as a "strong concept" [42] - somewhere between an "instance" and a "theory", in that it is more abstracted than any particular instance, but does not have the generality of a theory.

This concept has been applied much in HCI - a survey paper by Velt et al. in 2017 found 60 papers which 'seriously engaged" 
with trajectories [84], applying the framework in design for fields such as music [7, 12], theme parks [18], arts [1, 23, 25], museums $[24,62]$, games $[14,53]$, theatre $[16,28]$ and even magic [54]. One commonly recurring theme in these papers is the inclusion of additional, and often situational types of trajectory. Some examples include "interpretive trajectories" [63], "group", "multiscale" and "evolving" trajectories [23].

The trajectories literature is broadly focused on the practicalities of interaction - indeed, the concept is drawn from (often ethnographic) studies of interaction: what people did, said, etc. and how they engaged with an experience. Here, we suggest it is possible and desirable to consider how a user feels through an interaction, both in body and mind - that is, a soma trajectory. The idea of a soma trajectory was introduced by Tennent et al. [80], who argue that somatic feelings may change at different points in an experience, but do not explore in detail how this may happen and how these trajectories may be described. In this paper, we unpack the concept, reflecting on the complexity of articulating soma experiences as trajectories using our personal experiences of the examples described by Tennent et al.

\section{SOMAESTHETIC CHARACTERISTICS AS DIMENSIONS}

This paper reflects on several experiences created using soma design. Thinking about these experiences, our own experiences as soma designers and our somaesthetic appreciation has led us to recognise that the 'soma' is a deeply complex space. We recognise the temporal nature of these experiences, that they take us on somaesthetic journeys. The authors of [80] posit the idea of soma trajectories - recognising that these experiences are not snapshots in time, but journeys through a range of sensations and feelings. Here, we expand on that insight.

We recognise that soma cannot readily be quantified in and of itself. Instead, our reflections and discussions around doing these soma design activities led us to recognise some characteristics of somaesthetic experiences, which may be considered as dimensions in which we can move between seemingly opposing values: comfortable<-> uncomfortable, familiar<->strange and inside<$>$ outside. We present them as dimensions that range between extremes - not because we see them as being quantifiable - but because exploring extreme and opposing end points can be useful for untangling an experience.

We began this journey with a workshop, first reported on in [80], but briefly summarised here for convenience. Two design studios, The Somaesthetic Design Research Group, based at KTH Royal Institute of Technology, Sweden and The Mixed Reality Laboratory, based in the University of Nottingham, UK, came together for a soma design workshop exploring the theme of balance. This consisted of a number of sensitisation activities, including body scans, Feldenkrais and contact improvisation, and a series of experiences based around balance, using some pre-prepared equipment including a virtual reality tightrope, a flying harness, prosthetic limbs and a guitar. We also made use of the 'soma bits' toolkit [91] a set of pre-prepared objects and materials which allow us to create various sensations of stretchiness, softness, hardness, heat, vibration etc. as well as some biosensors - principally electromyography (EMG) sensors which when applied to specific muscles allowed us to visualise of sonify the activity of those muscles. All the activities in the workshop were documented with body maps [50] as well as notes and some video.

All of the authors of this paper were participants in, or organisers of, that workshop. Following on from the workshop, the two studios kept in contact. More than a year of regular discussions, including further development of some of the prototypes and a follow on workshop on the guitar, reported on in [2] allowed us to deeply unpack our experiences collaboratively and at length. The discussion led us to synthesise a number of dimensions we wished to explore further. As a way of unpacking our experiences with respect to these dimensions, we drew on the trajectories framework as a starting point which subsequently led us to develop an instrument for visually representing these dimensions in order to articulate our experiences: The soma trajectories tool. Finally, authors drew out their individual experiences based on those reflections, and using our tool which appear as the charts in sections 5 and 6 .

The dimensions themselves came from joint design work and analysis between the two design studios: one studio focusing on what we might frame as comfortable, introspective and calm interactions, and the other studio focusing on the uncomfortable and thrilling - hence the comfortable<-> uncomfortable dimension. What might at first seem like an obvious dichotomy between comfortable and uncomfortable turns out to be more intricate and interesting, with experiences taking us back and forth between the two. Second, one of the studios had a particular commitment to soma design methods that are broadly framed under the header estrangement [88]. Estrangement methods allow us to characterise what is familiar and habitual in our lives through engaging with what is non-habitual. As the two studios used estrangement methods both during the design process and in the resulting design concepts during their collaborations, the familiar<->strange dimension became apparent. Third, while soma design is often characterised as engaging mainly with the first-person perspective and unique, individual somatic experiences, the boundaries between the self and others 'dissolve' to some extent during design work. In our joint work, we came to question what is inside the body and what remains on the outside; this became yet another dimension.

These somaesthetic dimensions represent design spaces in which experiences may affect us, though the experiences had not been designed to explicitly travel in a given dimension. These dimensions are not in any way exhaustive; indeed, we considered many others, such as expert $<->$ novice as a way of unpacking the relationship between domain expertise and our somaesthetic appreciation of that domain, and mindful<->mindless as a way of considering different theories that could explain what we experienced in our joint design work. We would argue that that 'somaesthetic dimensions' could represent any extremes that allow for travel between them, e.g. pleasure $<->$ disgust, tension $<->$ release, openness $<->$ closedness etc. However, we have chosen these three as interesting ways through which to examine our own experiences. Our dimensions are lenses to be temporarily picked up for a particular perspective on a soma experience before being put back down again.

In the following sections, we present our instrument: the soma trajectories tool, then we provide a set of case studies where we analyse some of our experiences using these dimensions and the 


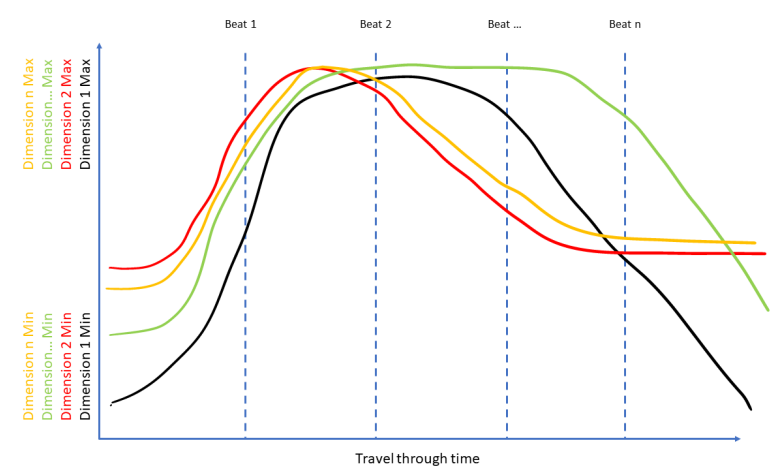

Figure 1: The Soma Trajectories Tool.

trajectories tool. We consider the meaning of each dimension, then discuss examples from our own work by drawing out trajectories of the experiences in that dimension - sometimes from the perspective of one individual's remembered experience, but mostly drawn from extensive discussion and reflection between many participants. We also consider examples from the broader HCI literature and everyday life that could be considered in the context of their trajectory in each dimension.

\section{THE SOMA TRAJECTORIES TOOL}

We developed an instrument to allow specifically temporal trajectories of somaesthetic dimensions to be articulated clearly. The tool (figure 1) is based on a simple linear chart with time on the $\mathrm{x}$-axis and whichever dimension of soma experience one wishes to articulate on the $y$-axis. The premise is one of open interpretation. The tool is a blank set of axes, and leaves it up to the user to determine what is placed on them. To describe it here, let us begin with the $\mathrm{x}^{-}$ axis. This will likely always represent time in some sense, however, we suggest that in most cases this is unlikely to be "clock time". In [8] Benford et al. discuss the difference between clock time and interaction time. We suggest that a user considers the $\mathrm{x}$-axis in terms of interaction time. If we look at many trajectory representations, such as those in [9] we see that they are inherently built around travel through something and usually this is a progression through events, stages or interactions. While our tool has the look of a time series, we suggest that it should be simply seen as a representation of progression through an experience. To enhance this representation, we include the notion of beats a self-defined set of 'important points' in the experience through which we are travelling. These may be spaced out however the user sees fit. We have spaced them evenly in our own charts, but this is not a requirement. They could be spaced to allow the chart to more clearly correspond to clock time, or to focus on specific events. Beats may be extrinsic - i.e external events, as those we have used later in this paper are, or intrinsic - i.e. feelings, sensations or interpretations. The decision about how to set up the $\mathrm{x}$-axis may be quite personal to the user showing what is important to them, or may be predefined by e.g. a workshop oragniser (even pre-printed) in order to make trajectories drawn by different individuals more directly comparable.

Turning to the $y$-axis, again, the tool is not prescriptive about exactly what should be represented here. We refer to these as soma dimensions and give several examples in the next section including comfort<-> discomfort, familiar $<->$ strange and inside $<->$ outside, however many other dimensions could be equally applicable from the very practical e.g. painless<->painful to the more esoteric e.g. hopeless $<->$ hopeful. As with the $\mathrm{x}$-axis an orchestrator wishing to specifically query certain dimensions of an experience may predefine which dimensions are used, or simply leave it to the users to decide what dimensions are of interest. A user may draw as many dimensions onto the chart as they wish. This allows us to see the interrelatedness of different dimensions when applied over the same temporal representation. Note that no values are added to the $y$-axis. This is because we would argue that soma-dimensions are not easily quantifiable, simply that they are dualistic in the sense that one can move between two extremes.

The tool is deliberately non-prescriptive about how it should be used. It is not necessary for drawn lines to be unbroken, or for only solid lines to appear. In figure 2, below, we see a user has added additional representations to the line to further characterise the representation. Looking to existing instruments used in soma design, and in particular body maps, with which we are most familiar through our own practice, the ambiguity about how to fill these in is a great strength: leaving the decisions of what to represent up to the user and simply providing enough scaffolding - in the case of the body maps, the printed figure - to encourage creative articulation. We hope the soma trajectories tool, with its light scaffolding of axes, affordance of representing something changing over time, and subsequently easy to understand notion of drawing charts, can be used in similarly creative ways, albeit with more of a focus on temporality.

\section{TRAJECTORIES THROUGH SOMA DESIGNED EXPERIENCES}

\subsection{Comfortable vs Uncomfortable}

$\mathrm{HCI}$ has rightly been concerned with maintaining or enhancing people's comfort. Although soma design does not claim to exclusively focus on comfortable experiences, these have tended to dominate its application to date. For example, it had engaged with designing for improved body awareness and relaxation [78], reflecting on one's affective states [3] and dealing with anxiety and issues of depression [90]. In contrast, some of the examples covered here set out to create thrill, risk taking and play, all forms of experience that may involve intentionally experiencing a degree of discomfort. Previous research into Uncomfortable Interactions has argued for deliberately designing moments of discomfort into user experience [11]. Benford et. al. argue that uncomfortable interactive experiences could potentially enhance entertainment, support social bonding or even contribute to personal enlightenment by demanding a deep commitment when engaging in an interactive experience, similar to experiencing interactive artworks [ibid].

Some explorations of soma design have engaged with various forms of discomfort. The Flying Harness (figure 2) as described in [80] is perhaps the most obvious case in point, requiring users to endure some physical discomfort in pursuit of the thrilling sensation of flying. The flyer needs to be tightly fastened with a harness wrapped around their waist, belly and thighs for safety reasons. The simple scaffolding rig from which they are suspended just above 


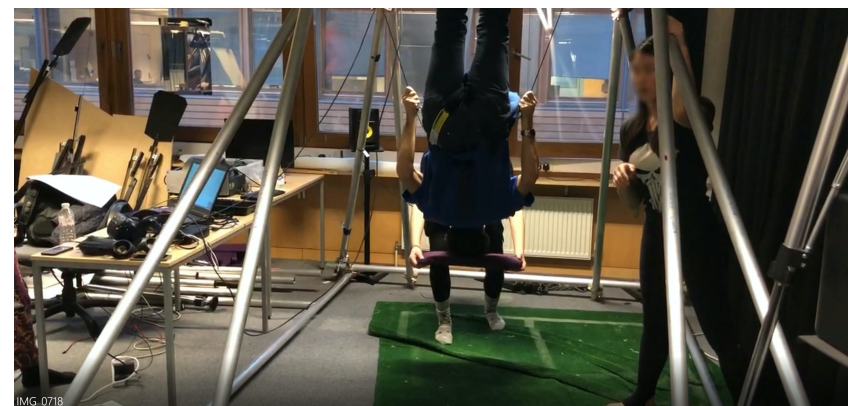

Figure 2: A participant held upside down while wearing the flying harness.

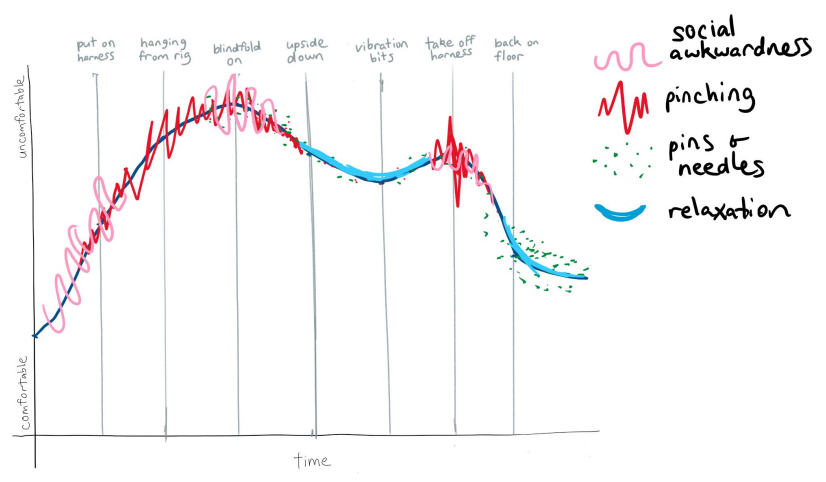

Figure 3: Flying harness comfort<->discomfort trajectory showing articulations of multiple types of experienced discomfort.

the ground only allows for rotation in the forward-backward axis. Participants were blindfolded whilst suspended and their group members held various soma bits [91] against body parts, such as a vibration bit against the small of the back, or a padded bit against the feet.

According to the first-person experiences of those who engaged with this prototype, it initially evoked visceral discomfort, even slight pain, in these particular areas of the body. The straps of the harness felt almost like they were 'cutting' into the flesh as gravity made these concentrated points of contact support the flier's entire bodyweight. The soma design process employed heat actuators which moved slowly along the back of flyer to comfort them as a response, but also experimented with less comfortable sensations, such as spinning fast or being "caught" suddenly by an elastic soma bit [80]. The Flying Harness also introduced discomfort through intimacy from being watched and even touched by unseen others while blindfolded with a VR headset, and loss of control, either through one's own inability to control unfamiliar movements or by being manipulated by others when powerless to easily stop or disengage (getting down from the harness is a lengthy process requiring external help). Figure 3 shows a trajectory of comfort drawn to articulate an experience of being in the flying harness.

Another experience that plays with this space was a contact improvisation activity used in one of our soma design workshops,

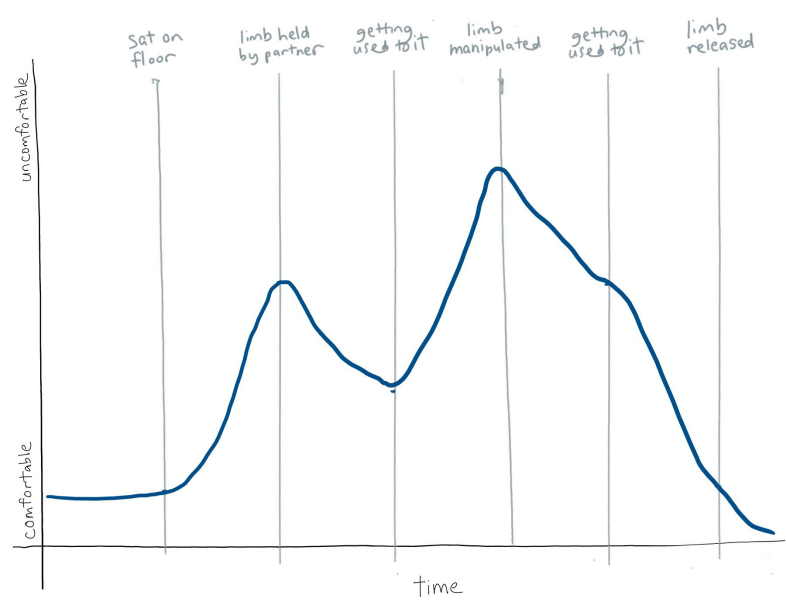

Figure 4: Contact improvisation trajectory of social comfort<->discomfort.

where it served as a sensitising activity to heighten somaesthetic awareness. Here, we were encouraged to sit while a partner manipulated our limbs. The first activity was simply having one's arm or leg held. Being partnered with an effective stranger initially made this experience socially uncomfortable for some participants, as it seems intimate. But after some time, the sensation became pleasant, comfortable - literally taking the weight off one's feet. The second stage of the activity where the limb was manipulated returned to the uncomfortable, then once more drifted back to some level of comfort as the activity became more familiar - then the sighing relaxation at the end of the activity where the limbs were released and very much one's own again. As shown in figure 4, this journey took us from mostly comfortable to significantly uncomfortable and back multiple times.

The journey in this case is one of social discomfort, but of course physical discomfort is another aspect of the same dimension. The experiences on the flying harness were very physically uncomfortable at first, then participants found ways to make it comfortable before the interaction shifted them back into uncomfortable - particularly at points where the impracticality of the harness impeded users from their intent.

Benford et al. [11] recognise the need to take us on journeys through discomfort and back again - a constantly uncomfortable experience may not be a pleasurable one - rather it is the journey that generates the thrill, from physical discomfort [15], to social discomfort [56] to "Horror Guilt and Shame" [32]. Soma designers have also engaged with this dimension, exploiting physical and social discomfort in pursuit of performative fun [87].

This is recognised in endless designs in the real world - the horror film that tricks us into believing everything is fine only to deliver a jump scare, the roller coaster that includes a smooth, fast run then a sudden breathtaking loop the loop, or the trip to the gym where the rush of endorphins (and the occasional postgym doughnut) make us feel comfortable again after the strenuous exercise. 


\subsection{Familiar vs Strange}

The Familiar/Strange dimension has roots in the concept of "defamiliarization" in romantic literature [70], where it was proposed that poetic language makes the ordinary world seem strange, disrupting our perception of everyday things. This concept has been later successfully imported into the design of novel kinaesthetic experiences [89]. Defamiliarisation is an accepted method within soma design [41, 89]. A common strategy is to reverse a habitual movement, emotion or thought. Try, for example, folding your arms and then folding them the other way around, or deliberately taking a deep breath when scared. This brings the habit of folding your arms or responding to fear with tensed muscles out of the tacit, unreflected knowledge realms into focus, allowing for explorations on how it is done and thereby alternative ways it could be done.

We discuss defamiliarisation not simply as a sensitisation goal, but more broadly as a strategy for designing interesting experiences. Here, we might consider to what extent we are adopting a designer's or a user's perspective when discussing soma design. Some of the time we adopt the designer's perspective, considering how soma design can offer new insights into a user's bodily experience. At others, we might embed soma principles into the end user experience, encouraging users to acquire new understandings, and perhaps consequently alter their own experience, their bodily interactions. This reflects a wider methodological debate in HCI about the relationship between user and designer. Historically, these were seen as somewhat separate, with designers being largely separated from and designing for users. However, various movements within HCI have sought to break down this barrier, including Participatory Design [4], Co-Design [33] and variants of these that seek to bring users directly into the design process, or Research Through Design [30] and its variants in which the designer is often the user.

A journey of defamiliarisation and then refamiliarisation, with novel couplings between movement-emotion-thought, can serve to close the gap between users and designers. As expert practitioners in their own domains, users may become more open to new ways of reimagining their current bodily practices, while designers become more open to breaking their familiar modes of design thinking. With both parties experiencing defamiliarisation, they can find common ground and work together on a level playing field, then reabsorb new learnings into their own practices. Conversely, processes of refamiliarising help both parties embed new insights back into their established practices, refining specific interaction skills for users and design thinking for designers.

Many soma design practitioners will be familiar with moving in this dimension as a design strategy - e.g. slowing down movements to better understand them $[66,89]$. At its most basic level, virtually any experience imaginable has a simple trajectory of strange to familiar; this is just the concept of learning. But moving back and forth between the dimensions is perhaps less common. Our VR tightrope experience, shown in figure 5, serves as an example. Based on the floor with just a 'virtual' tightrope, the experience begins in very familiar territory. The user must simply walk from one end of a room to another along a 'tightrope' a few centimetres from the ground. This is physically represented by a wooden beam on the floor in the real world. In the next scene, the same tightrope is strung between two virtual precipices. Though this is a familiar

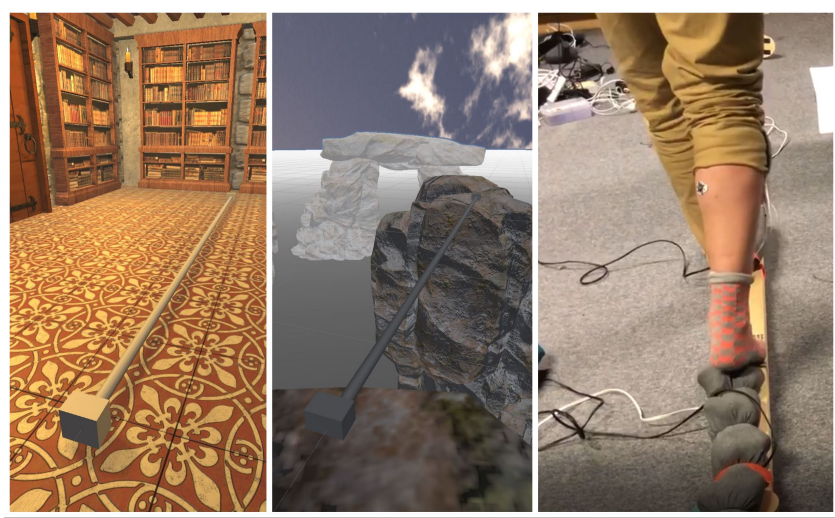

Figure 5: The tightrope VR experience

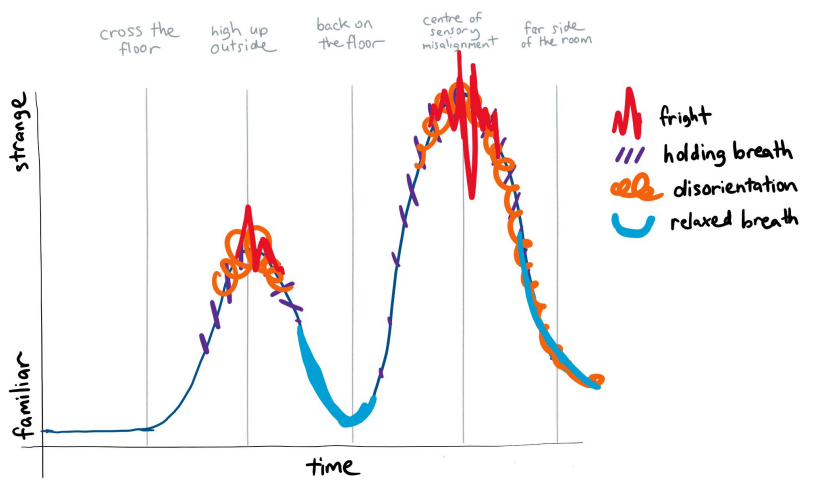

Figure 6: A walk on the VR tightrope articulated through the familiar<->strange trajectory

setting (where else would a tightrope be but high up?), it is an unfamiliar experience for most. The user is then returned to the familiar room once more, this time with a sensory misalignment [52] that tilts their vision as they traverse the tightrope. The first few steps are easy, but as the effect is increased in a confluence envelope [81], the task of walking becomes increasingly strange. As the user passes the centre point of the tightrope, the misalignment decreases and the user mostly returns to the familiar, albeit with some lingering disorientation. Figure 6 shows an articulation of this journey with some annotation about the participant's feelings and actions as she traversed the virtual tightrope.

In a soma design activity involving a guitar, some participants lacked experience with the instrument. They expressed feeling inadequate as they became self-conscious about the 'rules and techniques' involved in guitar performance. This resulted in the guitarists of the group having to illuminate the design space for guitars, whilst the non-guitarists led the somatic explorations with the instrument, such as facilitating the estrangement with the artefact. In other words, the guitar was made strange to the guitarists when its materiality was intervened by changing the expected ecology of the practice, specifically by making the strap stretchy and the pedal board wobbly as seen in figure 7 and reported in [2]. While it may be reasonably easy to make experts feel like novices through 


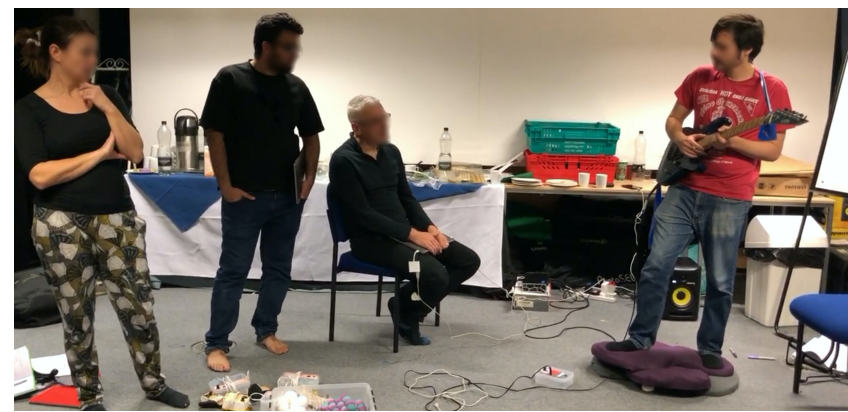

Figure 7: Exploring the soma space of the guitar.

defamiliarisation, the task of turning the strange familiar is more challenging. Soma designers sometimes engage with a particular field to gain better somaesthetic understanding of it. In [74], Shusterman deeply unpacks the field of gastronomy to better understand the somaesthetics of eating and drinking. But understanding of a field is not the same as expertise. The time and practice necessary to become an expert at a specific skill is realistically out of range for a designer exploring a particular space, and as such, there is a need to elicit design space knowledge. One approach to achieving this from HCI is the use of ideation cards, e.g. [6, 86] which seek to distil specific design space knowledge into manageable, bite-size chunks. However, kinaesthetic skills such as the muscle memory associated with playing a guitar over many years, as well as the breadth of field-specific knowledge, such as the fingering of chords, cannot easily be captured through some sample experience. If the 'strange' experience we wish to familiarise is an expert kinaesthetic skill, then we must turn to alternative strategies to sensitise ourselves as soma designers to those skills. In this case, we may think of mid-range prototypes that embody the playing experience with the guitar, such as strumming and fretting, but with much less physical demand - as explored by Harrison and McPherson when making accessible guitars and evaluating them with guitarists and non-guitarists [34].

A way we have explored this is with a 'shared guitar' where two people, one expert and one novice, work together to play a single guitar [2]. The expert guitarist fingers the chords on the guitar, allowing the novice guitarist to strum the strings. For the novice, the result of this is a feeling of "playing the guitar", albeit with some limitations, but far more successfully than they would alone. By contrast, the guitarist's practicable expertise is reduced. Tapping aside, fingering does not produce sound by itself - so the expert finds themselves sharing control with the novice, and ultimately producing less "perfect" sounds than they otherwise would have. Interestingly, the two participants cannot trade places. The fingering of the chords is by far the more difficult task, unlike strumming which can be performed inexpertly with good success. Without the muscle memory and calluses formed over long practice sessions, it is simply not possible to produce a reliably good sound, and certainly not to switch between chords or finger a complicated lick. But with a little practice, the two players together can produce music. The chart in figure 8 shows the trajectory of the two participants' journeys through the familiarity and strangeness of playing the

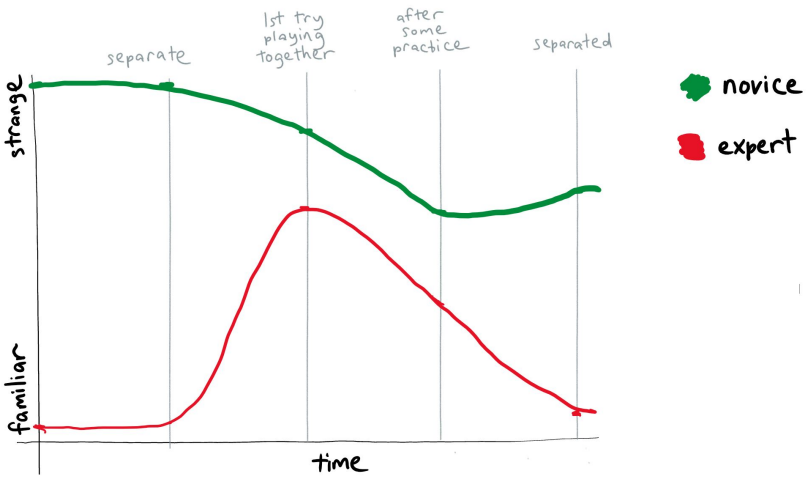

Figure 8: Making the familiar guitar strange for an expert and the strange guitar familiar for a novice.

shared guitar. Notice that for the novice player, the experience starts out strange, but ends with the guitar more familiar: they have had a sense of being able to play it, felt the vibrations that strumming creates, the feelings of the strings on their fingers. The relationship with the guitar is changed in the longer term. The novice has not 'learned to play the guitar' per se, but they have learned what it might feel like, making the artifact and their relationship with the artifact fundamentally less strange through this interaction.

The breath-controlled bucking bronco in [55] begins as a familiar object. Most people have seen (if not ridden) one, and it draws on the metaphor of the untamed rodeo horse. But when a rider climbs onto it, it is immediately unfamiliar. This bronco is smooth and hard to sit on, it is uncomfortable and strange. Then it starts to move, controlled by the user's breathing - which immediately makes the action of breathing unfamiliar. Over time, the rider (may) develop an understanding of how the system works and feel they have a sense of control over it. In this case, there is a mapping between familiarity and sense of control [13], but then the ride exerts its on control over its rider and they are ultimately thrown off. As they exit the ride, they reassert control over their body, and at the same time reassert their familiarity with their bodily action. In the brain-controlled film from the same paper [ibid], the viewer begins in unfamiliar territory, watching a film but then - the film they are watching appears to cut randomly - this is suddenly not what they expect from a film. Over time they regain control, at least over the cutting if not the content, recognising that it is mapped to their blinking. The film is long enough to become familiar with the interaction through a sense of control. Sandlin's 'backwards brain bicycle' [65], with which the rider must pedal backwards to move forwards and turn the handlebars in the opposite way from which they want to turn, is another example of taking a familiar activity - as Sandlin says "you never forget how to ride a bike" - and making it strange. The movements themselves are not unfamiliar but our deeply ingrained affordances for the mapping between them are wrong. A similar thing happens when drivers who have never or rarely towed a trailer have to reverse it - the mapping between turning the wheel and the direction of travel of the trailer is different to the deeply ingrained affordance. 
A common strategy in game design is to slowly introduce new mechanics, especially if it is something for which the player has no prior expectations. One excellent example is Valve's Portal (www.thinkwithportals.com), in which the portal gun (which creates a dimensional link between two fired "portals") is an entirely unfamiliar object. The game slowly familiarises the player with this by showing how common (gaming) situations like passing a locked door can be subverted with the new object, before slowly introducing more layers of complexity as the object itself becomes familiar. Many games also exploit the idea of taking something familiar and putting an unfamiliar spin on it. For instance, 'Rocket League' (www.rocketleague.com) takes the familiar idea of driving a car and gives the player the unfamiliar task of using that car to play soccer. The enduring popularity of the game, however, certainly suggests that many users have journeyed back to familiarity.

Shusterman sees these transformations as a process of attending and learning to appreciate. As he frames it: "We need a proper feel for our tools in order to use them most effectively; and this includes the use of one's own body in using other tools. For the body is our indispensable tool of tools, the necessary medium of our being, perception, action and self-presentation in the world." [71]. Our bodies are mouldable and we can learn to reap more satisfaction and aesthetic appreciation through our senses if we choose to attend to them.

\subsection{Inside vs Outside}

The skin is traditionally seen as being a critical boundary of the body and one way of defining the bodily self. We can see, i.e. perceive with our eyes, our "external", fleshy body - our moving limbs and parts, and our skin as the boundary between our "external" and "internal" body -our organs, cells, muscles etc., - which we cannot see, but instead feel or imagine. However, the boundary may be considered malleable. Take the example of a prosthesis - is this a part of our body or a separate piece of technology? - what if it were directly connected to our nerves/muscles?

The Inside/Outside dimension has roots in phenomenological concepts of interaction such as tool use [37] and the concept of instrument in Merleau-Ponty's Phenomenology of Perception [57], where objects become extensions of the sensory apparatus, incorporated into our body schema. Long tradition in HCI has adopted these concepts into embodied interaction and, more recently in the emerging field of human-computer integration. Many practitioners of HCI and related disciplines have argued for reducing the boundaries between bodies and technology by developing, for example, body-worn computers or robotic devices that have the potential to "extend the malleable nature of our self-image" [47]. Concepts such as augmentation [51] and integration [20,21] depict humans and computers acting in symbiosis.

In the case of integration, this symbiosis can be articulated in two dimensions [58]. The first is agency, where machines and users can take turns leading the interaction. The second is scale, where machines and humans can be integrated at different levels: on the skin (such as wearables) $[44,79,82,83]$, beyond the skin (voice, gesture, ambient and other 'remote' interactions) $[19,76]$ and inside the skin (implanted, edible) $[29,48]$. This suggests that the boundaries between humans and computers are liminal and open to new challenges and opportunities at the meeting between the two, such

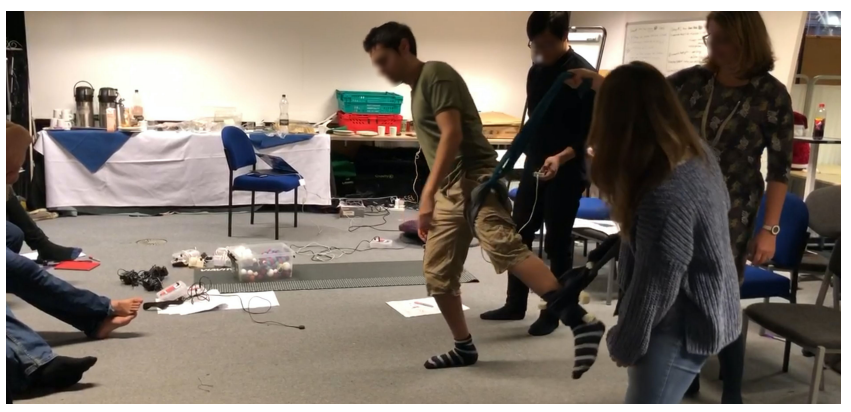

Figure 9: String Figure Experience - dancing with a disobedient limb

as designing bodily prostheses (one of our case studies), or designing for feeling as one with a vehicle when driving. Questioning the boundaries between humans and technology also invites reflection on the boundary between 'inside' and 'outside': separated by the skin, breathing in and out, ingesting and excreting. Thinking through these boundaries allows designers to re-define them, and thus challenge not only where the soma begins and where it ends, but also where the boundaries of experience lie.

Consider the string figure experience (figure 9), where participants had to imagine a limb that had a 'mind of it's own' - an exploration of dance where a part of one's body was separated from control. We simulated this by attaching cloth straps to the dancer's calf and thigh so other members of the team could control them. The dance experience became one of negotiating control with one's own body. This could serve as a conceptual stand-in for novice kinaesthetic skills where one's body is unable to do what is asked perhaps lacking the range of motion needed. But this was beyond being simply unable to perform the controlled limb; it actually became a separate performer in its own right, creating an intriguing partnership with a part of one's own body, and encouraging the dancer to question the boundaries of their body and soma.

As we began to dance, our body behaved as we expected and we were unfettered. As our group began to take control of our limbs, we lost some agency over our body. The external influence started to exert itself in such a way that it restrained us, or actively pulled us. We were no longer 'at one' with our own body - rather those who controlled our limbs shared control with us. Over time as we learned how to work together, that action could even be considered a part of us (at least as far as the experience goes). It should be noted that the group members pulling on the straps were a stand-in for a 'disobedient' prosthesis - so the notion of it becoming part of us, or perhaps beginning as part of us, separating from us and returning might be more tightly aligned to our own body than the group experience - nevertheless the group does have access and licence to control our limbs - something we also saw in the contact improvisation discussed above in section 5.1. The chart in figure 10 shows a trajectory articulation of the inside<->outside felt relationship during this experience.

Another activity which took us on a journey between inside and outside was an electromyography (EMG) soma bit applied to our calf muscles on the tightrope discussed in section 5.2 in which the internal process of the body (in this case, muscle contraction) 


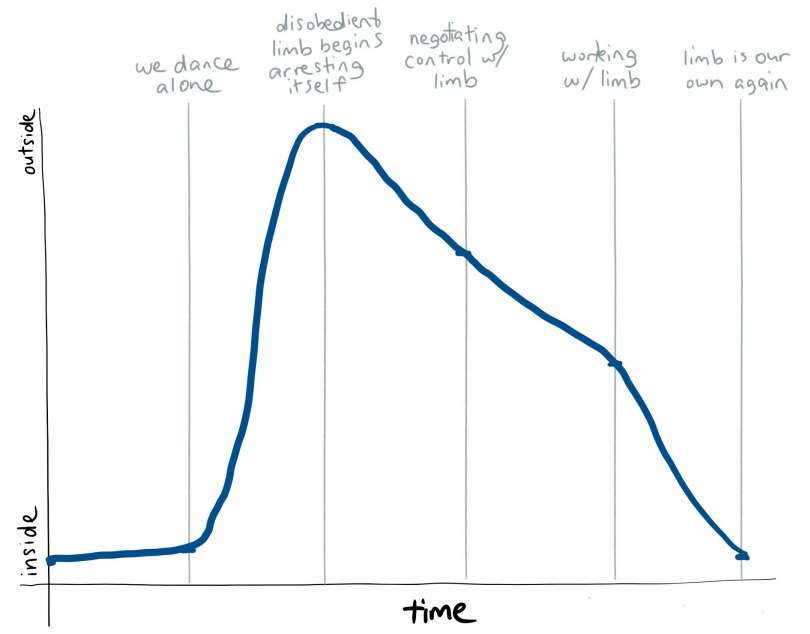

Figure 10: Our sense of inside<->outside through the string figure dance.

was deliberately externalised - sensed with a different sense (with audiographed sound) and forced us to confront our bodily process in a different way. This externalisation for all to see and hear of an internal bodily process - the movement of our muscles under the skin - speaks strongly to questioning of the boundaries of the body, with technology penetrating that boundary (albeit not physically breaking the barrier) and broadcasting its findings. This led to three interesting observations around the experience: 1) whether spectators could predict from the audio (or visual charts) when the balancer was about to fall off, 2) how sensing our muscles through a different medium might change the way we 'do' balancing in this activity and 3) how it felt to be 'exposed' in this unusual way. Figure 11 shows an articulation of the inside<->outside trajectory of walking along the balance beam. In this case, the chart refers to a sense of exposure - we start off feeling our body is more or less private. Then as the sensors are attached, we are very aware that our muscle movements are being broadcast. As we start the task, we begin focusing more on our self; we can still hear the sonified EMG, but it is more 'for us' to use. Then as we fall off, the sound changes startlingly and we become more aware again - it heightens our embarrassment as we feel that not only have we failed in the task, but the way in which we failed - our inability to make our body do what we wanted has been broadcast to the spectators leading from this into immediate discussion of the event extends this sense of exposure of what is beneath our skin.

The language of martial arts is heavy with phrases like, "let the sword be an extension of your hand". This is broadly a reflection of Heidegger's 'ready to hand' vs 'present at hand' argument [37], albeit taken to an extreme. If we do not focus on the hammer, but on the task of hammering, is there a point where the hammer becomes simply an extension of our body? What if the hammer is attached to a prosthetic arm? The blurred boundary of the body is an interesting space. Surely the very term embodiment suggests reaching out with our 'boundary' to include external things in our body. Embodiment and disembodiment are both intrinsically linked to our sense of the

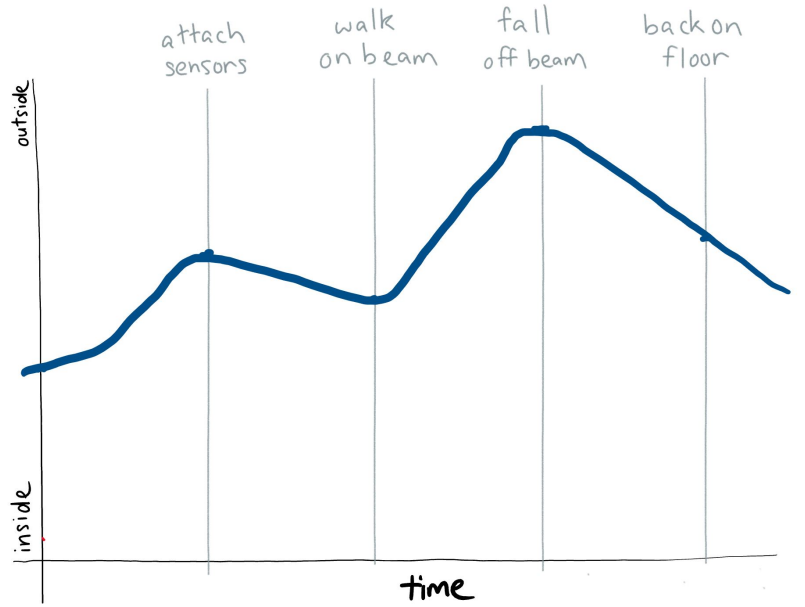

Figure 11: Exposing the workings of our muscles on the tightrope articulated through the inside<->outside trajectory.

boundaries of our body - but the transition is necessarily two way: When we are disarmed by a more skillful opponent, that sword which was an extension of our arm is suddenly very much an external object. A simpler example is that of food. We consume an external thing and some of it becomes part of our body - admittedly sometimes it makes us unwell and violently leaves our body. But fundamentally, eating is an exercise in crossing the boundary of our body - and can be one of the most pleasurable of experiences. Thus the boundary of the body is both fuzzy and permeable - either deliberately or not. When we get tattoos or piercings, we forcibly penetrate the skin in the name of art and self-expression. While a piercing is removable, so can remain at some level outside, a tattoo becomes a (mostly) permanent part of our body. When we consider the trajectories of soma experiences, we can imagine not only how parts of the experience might cross this boundary (perhaps multiple times), but also how that boundary itself might move.

\section{INTERCONNECTED TRAJECTORIES}

The dimensions discussed above do not exist in isolation. Often something that affects one will in turn affect the others. Somaesthetics as a discipline is predicated on the interconnectedness of the body and mind, the interconnectedness of the senses and the emotions, of the hand and the foot. It is no surprise then, that when considering dimensions in soma design these dimensions contain some crossover, like the vibrating string of a guitar affecting one will affect the others. Consider the example of the string figure, described above in section 5.3. An articulation of it in all three dimensions (figure 12) shows much similarity between the curves. Though the starting points may be very different, all of the trajectories show a peak at the point where the other members of the group start influencing the dancer's limb. The external influence is uncomfortable both socially and physically; it is strange - our limbs do not normally move out of our control like that; it takes our attention outside our body, since outside influences are 


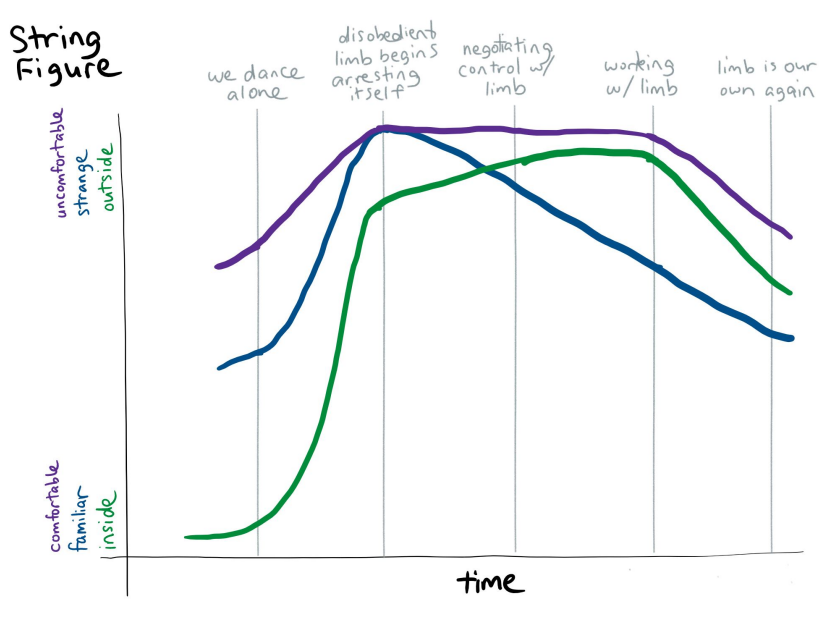

Figure 12: String Figure Soma Trajectory.

exerting themselves on what is normally controlled inside - our expertise as a dancer is artificially reduced as a second person is now sharing control of our body with us, and the activity we were doing is suddenly foregrounded - we cannot just dance, we have to come to terms with the intervention. After this, the dimensions diverge somewhat. The activity remains uncomfortable, and we remain acutely aware of the outside influence, but as we negotiate control with the person controlling our limb, the feeling becomes less strange, and we are more able to relax into the activity and get back into performing the dance, rather than fighting with an unruly limb.

Conversely, consider the augmented tightrope (figure 13), as described by the authors of [80], in which an expert balancer walks over a balance beam which has a series of vibration soma bits placed in the centre of the beam, then a series of heat soma bits placed further along. The authors of that paper noted that the balancer lost his ability to balance as the sensory information was overloaded by the vibration bits. Drawing out the trajectory for this experience in all three of our dimensions reveals that these trajectories behave more independently from the beginning. Certainly there is a connection between them. As the balancer reaches the point of intervention in the act of crossing the tightrope - the vibration bits - they quickly transition from familiar to strange as intended by the activity. The dimension of comfort, however, is largely unaffected by this specific event - it does increase, especially in terms of social discomfort as others watch them struggling with the task, but as tightrope walking is a performative skill, this form of discomfort is more normalised, and as such is more spread across the whole activity than sharply focused on one point. While the balancer's bodily focus does shift from outside to inside, as he has to return to his body and reconsider about how to balance on this changed object, the effect is less pronounced than in the case of string figure - where the dancer was losing agency over their own body.

Some of these experiences involve multiple participants, such as the case of the shared guitar (section 5.2). Aspects of this togetherness also have an effect - the necessary closeness may affect comfort, while the expertise - and thus familiarity with the artifact

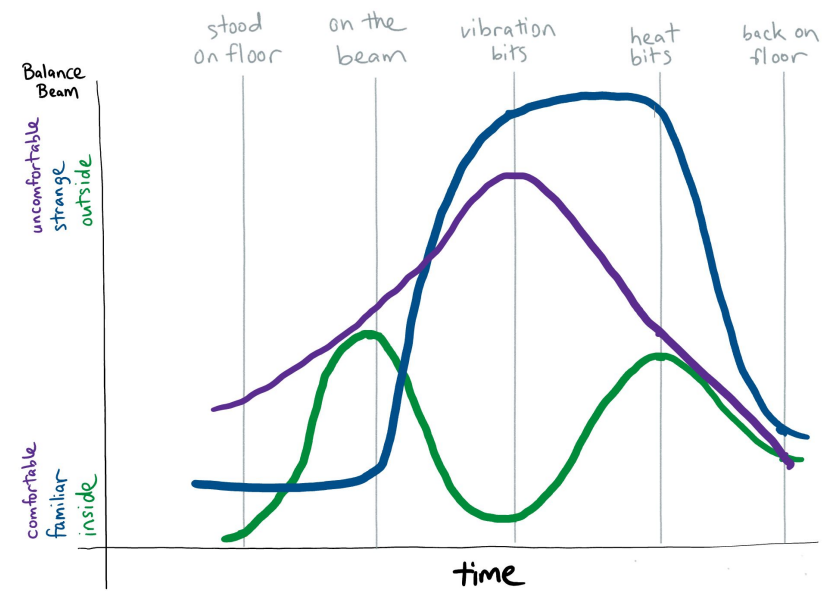

Figure 13: Balance Beam Walk Soma Trajectory.

of each player has an effect on the 'group' familiarity of the pair thus the 'output', in this case the music. One player's familiarity with the instrument may 'rub off' on the other player, causing them to feel more confident, more comfortable and more able to perform.

While we have discussed each of these dimensions as if they existed in a vacuum, they do not, indeed they cannot - they are fundamentally linked, both by the nature of their description - in that the lines between each of them are quite blurred, and by the fact that attempting to deliberately intervene in one is quite likely to affect others. Of course, it is necessary to recognise that these dimensions are in no way an exhaustive list of 'the dimensions of the soma', as we shall see in the next section.

\section{DISCUSSION}

\subsection{Representation of Soma Experience}

Soma experiences are felt. They are inherently first person and made of a complex, interconnected set of bodily and emotional interactions and sensations which colours how we engage with the world beyond our selves. This makes them fundamentally difficult to describe. As simply saying, 'you had to be there' is analytically unsatisfactory, it is necessary to consider methods of capturing and articulating the feelings these experiences create. At the same time, these methods should possess a creative openness to allow for a plurality of felt soma experiences.

So far, we have used body maps [46] in our design processes, workshops and teaching to accomplish this. They are a simple, yet deep, way of facilitating self-reflection, sharing experiences in a group and documenting a somatic experience. A body map consists of a paper sheet with two outlines of a human body to be freely drawn and written on, along with suggested adjectives that can be used before and after a soma experience. Figure 14 shows an example of how these sheets might be filled in. In our design processes, we have typically used them over a longer time period with different kinds of bodily practices, resulting in several body maps from various occasions and participants. These are then analysed to find experiential qualities of interest. Such qualities can be feelings of 'connectedness', 'embracement' or 'floating' etc., 


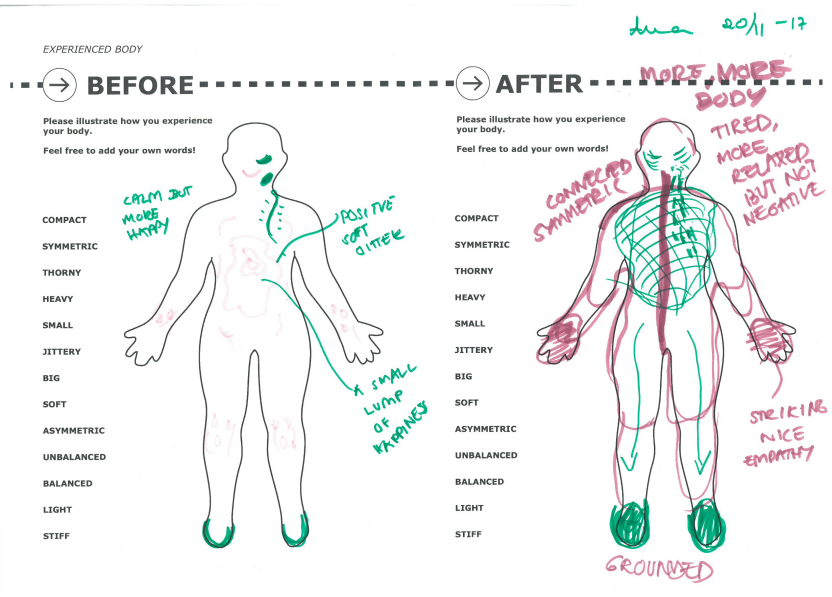

Figure 14: An example of a body map, as used in soma design practice

which can then be played with and altered over time in the design process. For example, if one wanted to work with connectedness in the experience of moving heat, the sensation of connectedness can be orchestrated by moving heat around the body in different ways to create change and interest in the soma experience being designed.

But body maps only partially reflect a soma experience. They exist as a snapshot or state representation. While a series of states can be used to infer change - and thus temporality [60], they are still inherently static. We suggest that soma trajectories might serve as an additional soma design tool to further tease out these complex experiences. We suggest that they may well be used in combination with body maps, since each brings its own aspect of articulation. We will discuss three benefits of using soma trajectories as an additional tool to body maps: to capture temporality at a much finer granularity, to allow for comparison, and to support re-feeling.

First, the body map is fundamentally momentary, a static image or set of images of a bodily experience. This does not rhyme well with the fact that any experience has a temporality and that our soma is inherently dynamic. The body map in itself does not really support dynamic experiences happening over time, e.g. a sensation that starts in the neck and moves down along the spine. Moreover, this static articulation of the body poses limitations when one wants to articulate a movement performed and its impact on the body. The before and after portions of the sheet provide 'bookends' of the experience, but does not express the temporal flow. As discussed above, analysis of several body maps used as documentation of soma experiences in a design process can aid the extraction of interesting qualities or dimensions in the experience, including through inference, some level of temporality, but these still lack the 'in experience' temporal aspect. The complementary use of soma trajectories may serve to fill this gap, as they provide the opportunity to map aspects of an experience over time and allow designers to play with them. In our examples above, we see that some journeys can be quite complex with multiple 'beats'. Any temporal articulations need to include key points in the experience as touch points for design consideration, since the experiences themselves are temporal and changing in nature. Even something as apparently simple as walking along an un-augmented balance beam might have the touch points of 'step on the beam', 'find point of balance', 'travel', 'nearly fall', 'regain balance', 'reach end' and 'step off beam'. And that assumes we didn't fall off... These beats will of course vary for different participants, so accounting for plurality of experiences, it is necessary for people to determine what their own beats might be.

In our case studies above, we picked on a particular set of dimensions which we felt were common to the soma experiences we described. While they may be applicable on other soma experiences, it is important to find the unique dimensions for the specific soma design at hand. We chose them to show how rich it can be for analysis to pick a specific dimension (e.g. comfortable<-> uncomfortable) and unpack the journey within that context. For any given individual and any given experience, as there will be an unlimited number of potential dimensions to consider, it is important to choose the dimensions that might become guiding in the design, that have the potential of teasing out the key points in the experience. Depending on the desired somatic experience, it is important to find the right dimensions to draw the trajectory. For example, when describing her experience with the guitar, one of our participants referred to feeling self-conscious for a variety of reasons. While we could sneak that under the language of inside<->outside ("I was feeling exposed"), or comfort<->discomfort ("I couldn't relax with everybody watching me"), it would not explicitly capture the felt embarrassment. Easier then to draw a trajectory of embarrassment - or perhaps more than one trajectory, e.g. physical embarrassment at being unable to perform the task, social embarrassment because of the necessary closeness of the shared guitar and so on.

Second, the bodies in the body maps are intentionally drawn without any details to allow for open-endedness in the documentation of the experiences. But at the same time, this means that they are not prescriptive about how they should be used. There is the articulation of a body and some suggested terms, but it is up to the designer or participant to decide how to use them. The recorded map is a very personal one, and one that is quite difficult to interpret for an outsider. Instead, they serve as a way to encourage immediate reflection and as a notation system which can then be used to aid a discussion with others who have had the same experience. The first attempt at filling one out can be a little daunting - it is not clear what is expected, but we have seen with practice that they can be quite detailed. However, they do not provide a common language which makes them difficult to compare. The sharing of the experiences, in the moment, in a discussion based on the body maps is necessary in order to make an analysis at a later stage to extract the somaesthetic qualities of the experience.

Articulation is a long standing HCI challenge, elucidated by Schmidt and Bannon [68] who talk about the need for all parties to understand the work being done - drawing on older sociological work from Strauss [77]. The job of articulation work is to enable that understanding. In [22], Fischer et al discuss how the use of a shared data resource in the form of charts is an aid to the articulation of what a system is doing. We might then ask if the same method can be applied to reflecting on our soma experience? We draw out 'data' charts in an easily recognisable language as a means of helping us 
articulate the experience - what was our soma experiencing as we did this thing?

Of course, the charts might have the trappings of 'system data' and could look like quantification of the experience, but it is no such thing, it simply applies the same visual methodology. The actual meaning of a wiggly line on a chart still needs to be teased out, but as a complement to the body maps which may be difficult to directly compare, two trajectories drawn by two people over the same dimension may share patterns or characteristics which can tell us about the experience, or indeed may be very different which also tells us about the experience - take the familar<->strange trajectories for the shared guitar experience as shown in figure 8 .

One might make the case that reducing experience down to charts is impinging on creativity. The body map is intentionally very open-ended in terms of how they are filled in, relying on the creativity of their users. One might assume that the more rigidlooking trajectory representation would limit this opportunity for expression of an experience and for interpretation. In [31] Gaver et al. make the point that introducing constraints, in their case in interface, in ours by the inherent limitation of the axis framing, forces you to temporarily look at the world in a particular way and that these limitations on information might encourage ambiguity - which far from being a negative thing, is an opportunity to demand interpretation. Further to this, if the chart is presented in an open-ended way [75], this creates the opportunity for very free-form and creative articulations as well. Despite the obvious affordance of being a time series, the fact it is also a blank canvas allows it to be interpreted in many ways - this openness to multiple interpretations, reflects the work of Sengers and Gaver [69] who advocate designing for multiple interpretations of an interface. For example, the trajectories depicted in figures 3 and 6 show how the participant has gone beyond simply drawing a line and depicted some of the additional complexities of the experience using colours/shapes etc. As an alternative to fully choosing for oneself what the dimension (y axis) means, such a system could be used to ask direct questions for comparison by actually creating prescribed axes in advance, providing a way to directly compare participants' experiences either to one another, or to an expected result - or canonical trajectory (see the next section for more).

The third benefit has to do with the degree of facilitating remembering, or better "re-feeling" a documented experience. When returning to a body map later in time (e.g. after a few weeks), we noted that even though they provide a means of documentation that can be kept, stored, and retrieved later, it is often challenging to remember the exact experience, sensation or impact that an exercise has left in the body. The soma trajectories may go some way to supporting this as they contain more description of the stages of the experience in the 'beats', and a combination of a body map with this perhaps more regular articulation may be easier to recall, however we do not suggest that this articulation is a complete solution to this problem.

In general, we are not proposing that soma trajectories are a silver bullet as an articulation tool, but an additional tool to be applied within soma design to further tease out and support the articulation of these complex experiences. They are complementary to body maps, since each brings its own aspect of articulation. Indeed the activity of filling in the body maps may serve to suggest dimensions of interest to unpack in the soma trajectories. Both serve as boundary objects [77] - tools for articulation, as well as tools for both self and shared reflections. The trajectories provide a familiar medium and a representational language that, in conjunction with body maps [60], can be helpful in making sense of the interaction gestalt. Particularly, they resonate with our experience that these important phenomenological dimensions, rather than being static or a simply goals to be achieved, are in constant flux, and as such, they can inform the design, orchestration and evaluation of humancomputer-integrations [21].

\subsection{The wider trajectories framework}

The concept of trajectories is predicated on the notion that users take paths through an experience, whether deliberately designed or serendipitous [9]. From an interactional perspective, this may be as straightforward as a literal path through an exhibition [26], representing the order in which the user engaged with the exhibits, but in this paper we are considering the trajectories of our soma though an experience. Where is the journey taking place in this metaphor? Various options might be presented. We could, for example, map an emotional journey on something like Russell's circumplex model of affect [64], drawing a path between different emotions.

The trajectories framework as a whole, is a little ambiguous about axes. Benford et al's paper that first outlined the framework [10] defined trajectories as passing through experiences that were made up of space, time, roles and interfaces, but did not present these in diagrammatic form - there were no axes as such at all. Later work in 'Performing mixed reality' presents a number of different trajectory diagrams [9], often shown as lines passing through an undefined space, though more formal dimensions such as time did appear in the case of the temporal trajectories described in [8]. With our goal to represent the temporality of experience, it is easy to draw on time a necessary dimension to represent. In trajectory diagrams, even those that do not explicitly feature time, the wiggling line still typically represents the passing of time - as we travel through an interaction, even if the scale may not be consistent. Our decision was to create time-series-like model of articulation in an effort to be both familiar and readable in format while articulating paths through many complex spaces - we were after all trying to imagine something that could reasonably be applied in practice without requiring much instruction. However, we recognise that while our $\mathrm{x}$-axis may inded represent the passage of time, this may not be clock time, but rather more like movement between a series of points - what we have called 'beats', thus time may be expanded or compressed as necessary to facilitate representing the 'important' parts of an experience.

With 'time' on the $\mathrm{x}$ axis, this provides the freedom to imagine what might be on the y-axis - what is the 'space' we are travelling through? While the framework does not strictly require clear dimensions to be defined, we still need to ask ourselves what should be represented in that undefined space that we travel through. When thinking about articulating a somatic journey we need to consider the fact that the soma is not an inherently quantifiable concept. It is made up of so many interconnected aspects of body, mind, motion, emotion, sense, sensation and so on, all of which can be interpreted freely and none of which obviously lend themselves to a 'scale'. 
The dimensions described in this paper give us some concrete framings and examples with which to analyse our experiences, but we recognise that the $y$-axis could be literally any relevant dimension we might wish to represent: Physical pain, happiness, excitement, a tickling sensation in our big toe. The choice of what to articulate is less important than the reflective task of articulating it and the analytical opportunities such reflection may offer. Further, since we are dispensing with scale, The time series format allows us to put many interacting lines on a single set of axes where each line represents travel in a different dimension. The lack of formal y-axis scale combined with a consistent $\mathrm{x}$-axis showing time allows us to articulate the interactions between several dimensions.

Trajectories have been typically applied to experiences which have some form of associated narrative, whether as a dramaturgical tool e.g. in [27, 49] or representing a journey or journeys though an experience, e.g. in [24,59]. While not all soma-designed experiences follow this kind of structure, the concept can reasonably be applied to anything that has a temporal aspect to it - our soma is never a snapshot, it is an ever changing continuous set of interconnected sensations, emotions, reflections and influences. As such, a framework built around temporal descriptions offers a powerful tool through which to unpack and analyse our experiences within the language of somaesthetics.

In the definitive description of the concept [9], Benford et al. describe three forms of trajectory: canonical trajectories, which are prescribed by artists and represent intended journeys through the experience; participant trajectories which are inscribed by individuals engaging in experience and diverging from canonical trajectories through interactivity, but then reconverging through orchestration; and historical trajectories which represent the interleaved accounts of participants trajectories and support post-experience reflection. Let us consider each of these in turn.

7.2.1 Canonical Trajectories. What do we expect the participant to feel/do? The canonical trajectory is prescriptive by nature. Framing our design in such terms might suggest that soma trajectories should be used generatively, however as Velt et al. note in their survey of the trajectories framework [85], "how designs should be generated is not explicated by either the framework's originators or its users". Rather than taking a generative view, we might draw canonical trajectories of a design as a descriptive strategy to "clarify terminology [...], identify key concepts [and] guide further enquiry" as Bederson and Shneiderman put it [5]. As a concrete example, during initial exploratory work with the soma bits on the balance beam, the designers deliberately chose the order that walkers would encounter them with a view to creating a journey where the heat bits placed at the end of the beam would create a sense of catharsis or reward for completing the task. We might imagine using canonical trajectories as a heuristic approach to asses the early stages of a design - if we want to take a user on a journey through a specific sensation or emotion, what might that journey look like?

Looking back at some of the sensitising activities we have used in our soma design sessions - for example, the contact improvisation activity described in section 5.1, we recognise that these activities may be deliberately selected or designed for the type of experiential journeys they take users on. If we wish to run a session of designing socially uncomfortable interactions, an example like the contact improvisation might be a good choice - we could consider tailoring such an activity to address exactly what we want it to do - indeed we typically do exactly this, but soma trajectories gives us a language and a method where we can creatively tailor the relationship, by comparing and altering their correlation.

Broadly, canonical trajectories are speculative. When it comes to the soma, we can be less predictive about what a participant will feel because of the subjective nature of experience. We might make some guesses, but trying to use this as a generative approach to design may not be as straightforward as it looks at first glance.

7.2.2 Participant Trajectories. Participant trajectories represent a specific user's journey through an experience. As we have discussed in the previous section, this is where we see much of the practical applicability of the trajectories framework to the task of soma designing. We recognise that the temporal nature of the trajectories concept, combined with a notion of somaesthetic dimensions through which to articulate these journeys, is a strategy for post-hoc reflection, description, accounting and articulation of deeply subjective first person experiences. These may be comparable - if using the same carefully defined dimensions - as a strategy for comparative analysis, or simply descriptive. In either case they serve as a qualitative basis for analysing and unpacking a specific participant's experience. We can learn from participants' choice of dimensions, and from their articulated journeys through those dimensions. As an analytical tool, trajectories can help us to both reflect on and deepen our understanding of our own experiences, and thus help heighten our somaestheitc appreciation. By providing a common language through which to communicate, they also help us better understand the experiences of others.

7.2.3 Historical Trajectories. Historical trajectories represent the accounts of multiple users and are typically used to reflect on an experience as a whole. For us, as our approach in this paper has been to reflect on past soma design activities and soma designed experiences, the trajectories we have drawn in this paper have been largely historical. They are not the 'in the moment' participant trajectories, but rather a product of extensive discussion of each of the experiences over more than a year, built on the first person accounts of and discussions with many different participants. The production of these historical trajectories has seen us reflect on each of the experiences in turn, unpicking the complexities of each through a specific set of somaesthetic dimensions. We suggest that as with the participant trajectories, which do occur 'in the moment' the more considered historical trajectories offer the opportunity for further analysis of an experience, particularly with respect to the differences between participant experiences. Looking once more to the shared guitar example - it is the difference in experience between those users who start as expert and those who start as novice and their shared, reactive experience that makes that such a rich activity to explore. Flintham et al. in [23] discuss the concept of group trajectories - a form of historical trajectories that focus on the activities and interactions of multiple users together. While the authors of that paper were (mostly) referring to groups that go through an experience together and how the may share a common trajectory, we recognise here how certain groups of users' - for example those with expert domain knowledge - trajectories 
may cluster or share properties, even if they were not doing the experience at the same time, especially in certain dimensions thus allowing us to delve deeper and unpack why certain groups may have those similar trajectories. For shared experiences, such an approach may support the recognition of how each user affects the other.

\section{CONCLUSION}

In this paper, we have described how the trajectories framework may be applied as a concept in soma design. We have shown how it can be used as a first-person analytical tool for reflecting on our somaesthetic interaction with experiences, recognising the need to establish dimensions in which those trajectories take place. We have offered a practical, applicable method of capturing these soma trajectories as part of our soma design activities. For us it has been valuable to use trajectories to retrospectively reflect on these experiences, however we hope there will be other ways of introducing them to a process, e.g. drawn in parallel with body maps. Finally, we have shown how these trajectories can be used as a conceptual framing for first articulating and subsequently unpacking complex somaesthetic experiences.

\section{ACKNOWLEDGMENTS}

This work has been supported by AffecTech: Personal Technologies for Affective Health, Innovative Training Network funded by the H2020 People Programme under Marie Sklodowska Curie grant agreement No 722022, the Swedish Foundation for Strategic Research project RIT15-0046, and the Swedish Research council project 2016-04709, and by the UK Engineering and Physical Sciences Research Council grants: Living with Digital Ubiquity EP/M000877/1 and My Life in Data - EP/L015463/1.

\section{REFERENCES}

[1] Gabriella Arrigoni and Brigitta Zics. 2016. Fiction and curatorial practice: developing alternative experiences for digital artistic prototypes. International fournal of Performance Arts and Digital Media 12, 1 (2016), 82-94.

[2] Juan Martinez Avila, Vasiliki Tsaknaki, Pavel Karpashevich, Charles Windlin, Niklas Valenti, Kristina Höök, Andrew McPherson, and S. Benford. 2020. Soma Design for NIME. In Proceedings of the 2020 International Conference on New Interfaces for Musical Expression (NIME'20).

[3] Madeline Balaam, Rob Comber, Rachel E. Clarke, Charles Windlin, Anna Ståhl, Kristina Höök, and Geraldine Fitzpatrick. 2019. Emotion Work in ExperienceCentered Design. In Proceedings of the 2019 CHI Conference on Human Factors in Computing Systems (Glasgow, Scotland Uk) (CHI '19). Association for Computing Machinery, New York, NY, USA, 1-12. https://doi.org/10.1145/3290605.3300832

[4] Liam J Bannon and Pelle Ehn. 2012. Design matters in participatory design. Routledge handbook of participatory design (2012), 37-63.

[5] Benjamin B Bederson, Benjamin B Bederson, Ben Shneiderman, et al. 2003. The craft of information visualization: readings and reflections. Morgan Kaufmann.

[6] Ben Bedwell. 2019. VisitorBox core deck. (2019).

[7] Steve Benford. 2010. Performing Musical Interaction: Lessons from the Study of Extended Theatrical Performances. Computer Music fournal 34, 4 (Dec. 2010), 49-61. https://doi.org/10.1162/COMJ_a_00025

[8] Steve Benford and Gabriella Giannachi. 2008. Temporal trajectories in shared interactive narratives. In Proceedings of the SIGCHI Conference on Human Factors in Computing Systems. 73-82.

[9] Steve Benford and Gabriella Giannachi. 2011. Performing mixed reality. The MIT Press.

[10] Steve Benford, Gabriella Giannachi, Boriana Koleva, and Tom Rodden. 2009. From interaction to trajectories: designing coherent journeys through user experiences. In Proceedings of the SIGCHI Conference on Human Factors in Computing Systems. 709-718.

[11] Steve Benford, Chris Greenhalgh, Gabriella Giannachi, Brendan Walker, Joe Marshall, and Tom Rodden. 2012. Uncomfortable interactions. In Proceedings of the sigchi conference on human factors in computing systems. 2005-2014.
[12] Steve Benford, Adrian Hazzard, Alan Chamberlain, Kevin Glover, Chris Greenhalgh, Liming Xu, Michaela Hoare, and Dimitrios Darzentas. 2016. Accountable Artefacts: The Case of the Carolan Guitar. In Proceedings of the 2016 CHI Conference on Human Factors in Computing Systems. ACM, San Jose California USA, 1163-1175. https://doi.org/10.1145/2858036.2858306

[13] Steve Benford, Richard Ramchurn, Joe Marshall, Max L Wilson, Matthew Pike, Sarah Martindale, Adrian Hazzard, Chris Greenhalgh, Maria Kallionpää, Paul Tennent, et al. 2020. Contesting Control: Journeys through Surrender, SelfAwareness and Looseness of Control in Embodied Interaction. Human-Computer Interaction (2020).

[14] Elizabeth Bonsignore, Vicki Moulder, Carman Neustaedter, Derek Hansen, Kari Kraus, and Allison Druin. 2014. Design tactics for authentic interactive fiction: insights from alternate reality game designers. In Proceedings of the SIGCHI Conference on Human Factors in Computing Systems. 947-950.

[15] Richard Byrne, Joe Marshall, and Florian 'Floyd' Mueller. 2020. Designing Digital Vertigo Experiences. ACM Trans. Comput.-Hum. Interact. 27, 3, Article 19 (May 2020), 30 pages. https://doi.org/10.1145/3387167

[16] Teresa Cerratto-Pargman, Chiara Rossitto, and Louise Barkhuus. 2014. Understanding audience participation in an interactive theater performance. In Proceedings of the 8th Nordic Conference on Human-Computer Interaction Fun, Fast, Foundational - NordiCHI '14. ACM Press, Helsinki, Finland, 608-617. https: //doi.org/10.1145/2639189.2641213

[17] Brigid Costello, Lizzie Muller, Shigeki Amitani, and Ernest Edmonds. 2005. Understanding the experience of interactive art: Iamascope in Beta_space. In ACM International Conference Proceeding Series, Vol. 123. 49-56.

[18] Abigail Durrant, David S. Kirk, Steve Benford, and Tom Rodden. 2012. Pursuing Leisure: Reflections on Theme Park Visiting. Computer Supported Cooperative Work (CSCW) 21, 1 (Feb. 2012), 43-79. https://doi.org/10.1007/s10606-011-9151-1

[19] Sara Eriksson, Kristina Höök, Richard Shusterman, Dag Svanes, Carl UnanderScharin, and Åsa Unander-Scharin. 2020. Ethics in Movement: Shaping and Being Shaped in Human-Drone Interaction. In Proceedings of the 2020 CHI Conference on Human Factors in Computing Systems (Honolulu, HI, USA) (CHI '20). Association for Computing Machinery, New York, NY, USA, 1-14. https://doi.org/10.1145/ 3313831.3376678

[20] Umer Farooq and Jonathan Grudin. 2016. Human-computer integration. interactions 23, 6 (2016), 26-32.

[21] Umer Farooq, Jonathan Grudin, Ben Shneiderman, Pattie Maes, and Xiangshi Ren. 2017. Human computer integration versus powerful tools. In Proceedings of the 2017 CHI Conference Extended Abstracts on Human Factors in Computing Systems. 1277-1282.

[22] Joel E Fischer, Andy Crabtree, James A Colley, Tom Rodden, and Enrico Costanza. 2017. Data work: how energy advisors and clients make IoT data accountable. Computer Supported Cooperative Work (CSCW) 26, 4-6 (2017), 597-626.

[23] Martin Flintham, Stuart Reeves, Patrick Brundell, Tony Glover, Steve Benford, Duncan Rowland, Boriana Koleva, Chris Greenhalgh, Matt Adams, Nick Tandavanitj, et al. 2011. Flypad: Designing trajectories in a large-scale permanent augmented reality installation. In ECSCW 2011: Proceedings of the 12th European Conference on Computer Supported Cooperative Work, 24-28 September 2011, Aarhus Denmark. Springer, 233-252.

[24] Lesley Fosh, Steve Benford, and Boriana Koleva. 2016. Supporting group coherence in a museum visit. In Proceedings of the 19th ACM conference on computersupported cooperative work \& social computing. 1-12.

[25] Lesley Fosh, Steve Benford, Stuart Reeves, Boriana Koleva, and Patrick Brundell. 2013. see me, feel me, touch me, hear me: trajectories and interpretation in a sculpture garden. In Proceedings of the SIGCHI Conference on Human Factors in Computing Systems - CHI '13. ACM Press, Paris, France, 149. https://doi.org/10. $1145 / 2470654.2470675$

[26] Lesley Fosh, Steve Benford, Stuart Reeves, Boriana Koleva, and Patrick Brundell. 2013. See me, feel me, touch me, hear me: trajectories and interpretation in a sculpture garden. In Proceedings of the SIGCHI conference on human factors in computing systems. 149-158.

[27] Gesa Friederichs-Büttner, Benjamin Walther-Franks, and Rainer Malaka. 2012. An unfinished drama: designing participation for the theatrical dance performance Parcival XX-XI. In Proceedings of the Designing Interactive Systems Conference. 770-778.

[28] Gesa Friederichs-Büttner, Benjamin Walther-Franks, and Rainer Malaka. 2012. An unfinished drama: designing participation for the theatrical dance performance Parcival XX-XI. In Proceedings of the Designing Interactive Systems Conference on - DIS '12. ACM Press, Newcastle Upon Tyne, United Kingdom, 770. https: //doi.org/10.1145/2317956.2318072

[29] Pablo Gallego Cascón, Denys J.C. Matthies, Sachith Muthukumarana, and Suranga Nanayakkara. 2019. ChewIt. An Intraoral Interface for Discreet Interactions. In Proceedings of the 2019 CHI Conference on Human Factors in Computing Systems (Glasgow, Scotland Uk) (CHI '19). Association for Computing Machinery, New York, NY, USA, 1-13. https://doi.org/10.1145/3290605.3300556

[30] William Gaver. 2012. What should we expect from research through design?. In Proceedings of the SIGCHI conference on human factors in computing systems. 
937-946.

[31] William W. Gaver, Jacob Beaver, and Steve Benford. 2003. Ambiguity as a Resource for Design. In Proceedings of the SIGCHI Conference on Human Factors in Computing Systems (Ft. Lauderdale, Florida, USA) (CHI '03). Association for Computing Machinery, New York, NY, USA, 233-240. https://doi.org/10.1145/642611.642653

[32] Chad Phoenix Rose Gowler and Ioanna Iacovides. 2019. "Horror, Guilt and Shame" - Uncomfortable Experiences in Digital Games. In Proceedings of the Annual Symposium on Computer-Human Interaction in Play (Barcelona, Spain) (CHI PLAY '19). Association for Computing Machinery, New York, NY, USA, 325-337. https://doi.org/10.1145/3311350.3347179

[33] Mike Hales. 1994. Where are designers? Styles of design practice, objects of design and views of users in CSCW. In Design issues in CSCW. Springer, 151-177.

[34] Jacob Harrison and Andrew P McPherson. 2017. An adapted bass guitar for one-handed playing.. In NIME. 507-508.

[35] Christian Heath and Dirk vom Lehn. 2003. Misconstruing interaction. Proceedings of Interactive Learning in Museums of Art and Design (2003).

[36] Martin Heidegger. 2017. Ontologie: Hermeneutik der Faktizitat. Verlag Vittorio Klostermann. OCLC: 1023544141.

[37] Martin Heidegger, John Macquarrie, and Edward Robinson. 1962. Being and time. (1962).

[38] Kristina Höök, Caroline Hummels, Katherine Isbister, Patrizia Marti, Elena Márquez Segura, Martin Jonsson, Florian 'Floyd' Mueller, Pedro A.N. Sanches, Thecla Schiphorst, Anna Ståhl, Dag Svanaes, Ambra Trotto, Marianne Graves Petersen, and Youn-kyung Lim. 2017. Soma-Based Design Theory. In Proceedings of the 2017 CHI Conference Extended Abstracts on Human Factors in Computing Systems (Denver, Colorado, USA) (CHI EA '17). Association for Computing Machinery, New York, NY, USA, 550-557. https://doi.org/10.1145/3027063.3027082

[39] Kristina Höök, Martin P. Jonsson, Anna Ståhl, and Johanna Mercurio. 2016 Somaesthetic Appreciation Design. In Proceedings of the 2016 CHI Conference on Human Factors in Computing Systems (San Jose, California, USA) (CHI '16). Association for Computing Machinery, New York, NY, USA, 3131-3142. https: //doi.org/10.1145/2858036.2858583

[40] Eva Hornecker and Jacob Buur. 2006. Getting a grip on tangible interaction: a framework on physical space and social interaction. In Proceedings of the SIGCHI conference on Human Factors in computing systems. 437-446.

[41] Kristina Höök. 2018. Designing with the body: somaesthetic interaction design. The MIT Press, Cambridge, MA.

[42] Kristina Höök and Jonas Löwgren. 2012. Strong concepts: Intermediate-level knowledge in interaction design research. ACM Transactions on Computer-Human Interaction 19, 3 (Oct. 2012), 1-18. https://doi.org/10.1145/2362364.2362371

[43] Dewey John. 1934. Art as experience. New York: Minton, Balch, and Company (1934).

[44] Pavel Karpashevich, Eva Hornecker, Michaela Honauer, and Pedro Sanches. 2018. Reinterpreting Schlemmer's Triadic Ballet: interactive costume for unthinkable movements. In Proceedings of the 2018 CHI Conference on Human Factors in Computing Systems. 1-13.

[45] George Khut. 2006. Development and evaluation of participant-centred biofeedback artworks. Unpublished doctoral exegesis, University of Western Sydney (2006).

[46] George Khut. 2016. Designing biofeedback artworks for relaxation. In Proceedings of the 2016 CHI Conference Extended Abstracts on Human Factors in Computing Systems. 3859-3862.

[47] Sang-won Leigh, Harpreet Sareen, Hsin-Liu Cindy Kao, Xin Liu, and Pattie Maes 2017. Body-Borne Computers as Extensions of Self. Computers 6, 1 (2017), 12

[48] Zhuying Li, Rakesh Patibanda, Felix Brandmueller, Wei Wang, Kyle Berean Stefan Greuter, and Florian 'Floyd' Mueller. 2018. The Guts Game: Towards Designing Ingestible Games. In Proceedings of the 2018 Annual Symposium on Computer-Human Interaction in Play (Melbourne, VIC, Australia) (CHI PLAY '18) Association for Computing Machinery, New York, NY, USA, 271-283. https: //doi.org/10.1145/3242671.3242681

[49] Christopher Lindinger, Martina Mara, Klaus Obermaier, Roland Aigner, Roland Haring, and Veronika Pauser. 2013. The (St) Age of Participation: audience involvement in interactive performances. Digital Creativity 24, 2 (2013), 119129.

[50] Lian Loke and George Poonkhin Khut. 2014. Intimate Aesthetics and Facilitated Interaction. In Interactive Experience in the Digital Age, Linda Candy and Sam Ferguson (Eds.). Springer International Publishing, Cham, 91-108. https:// doi.org/10.1007/978-3-319-04510-8_7 Series Title: Springer Series on Cultural Computing.

[51] Pattie Maes. 2017. Augmenting the Human Experience. In Proceedings of the 15th Annual International Conference on Mobile Systems, Applications, and Services (Niagara Falls, New York, USA) (MobiSys '17). Association for Computing Machinery, New York, NY, USA, 1. https://doi.org/10.1145/3081333.3081474

[52] Joe Marshall, Steve Benford, Richard Byrne, and Paul Tennent. 2019. Sensory Alignment in Immersive Entertainment. In Proceedings of the 2019 CHI Conference on Human Factors in Computing Systems - CHI '19. ACM Press, Glasgow, Scotland Uk, 1-13. https://doi.org/10.1145/3290605.3300930

[53] Joe Marshall, Steve Benford, Sebastiaan Pijnappel, et al. 2016. Expanding exertion gaming. International fournal of Human-Computer Studies 90 (2016), 1-13.
[54] Joe Marshall, Steve Benford, and Tony Pridmore. 2010. Deception and magic in collaborative interaction. In Proceedings of the 28th international conference on Human factors in computing systems - CHI '10. ACM Press, Atlanta, Georgia, USA, 567. https://doi.org/10.1145/1753326.1753410

[55] Joe Marshall, Duncan Rowland, Stefan Rennick Egglestone, Steve Benford, Brendan Walker, and Derek McAuley. 2011. Breath control of amusement rides. In Proceedings of the SIGCHI conference on Human Factors in computing systems. 73-82.

[56] Joe Marshall and Paul Tennent. 2017. Touchomatic: Interpersonal Touch Gaming In The Wild. In Proceedings of the 2017 Conference on Designing Interactive Systems (Edinburgh, United Kingdom) (DIS '17). Association for Computing Machinery, New York, NY, USA, 417-428. https://doi.org/10.1145/3064663.3064727

[57] Maurice Merleau-Ponty. 1982. Phenomenology of perception. Routledge.

[58] Florian Floyd Mueller, Pedro Lopes, Paul Strohmeier, Wendy Ju, Caitlyn Seim, Martin Weigel, Suranga Nanayakkara, Marianna Obrist, Zhuying Li, Joseph Delfa, Jun Nishida, Elizabeth M. Gerber, Dag Svanaes, Jonathan Grudin, Stefan Greuter, Kai Kunze, Thomas Erickson, Steven Greenspan, Masahiko Inami, Joe Marshall, Harald Reiterer, Katrin Wolf, Jochen Meyer, Thecla Schiphorst, Dakuo Wang, and Pattie Maes. 2020. Next Steps for Human-Computer Integration. In Proceedings of the 2020 CHI Conference on Human Factors in Computing Systems (Honolulu, HI, USA) (CHI '20). Association for Computing Machinery, New York, NY, USA, 1-15. https://doi.org/10.1145/3313831.3376242

[59] Bettina Nissen, John Bowers, Peter C Wright, Jonathan David Hook, and Christopher Newell. 2014. Volvelles, domes and wristbands: embedding digital fabrication within a visitor's trajectory of engagement. In Proceedings of the 2014 conference on Designing interactive systems. Association for Computing Machinery (ACM), 825-834.

[60] Claudia Núñez Pacheco and Lian Loke. 2016. Felt-Sensing Archetypes: Analysing Patterns of Accessing Tacit Meaning in Design. In Proceedings of the 28th Australian Conference on Computer-Human Interaction (Launceston, Tasmania, Australia) (OzCHI '16). Association for Computing Machinery, New York, NY, USA, 462-471. https://doi.org/10.1145/3010915.3010932

[61] Marianne Graves Petersen, Ole Sejer Iversen, Peter Gall Krogh, and Martin Ludvigsen. 2004. Aesthetic Interaction: A Pragmatist's Aesthetics of Interactive Systems. In Proceedings of the 5th Conference on Designing Interactive Systems: Processes, Practices, Methods, and Techniques (Cambridge, MA, USA) (DIS '04). Association for Computing Machinery, New York, NY, USA, 269-276. https: //doi.org/10.1145/1013115.1013153

[62] S. Rennick-egglestone, P. Brundell, B. Koleva, S. Benford, M. Roussou, and C. Chaffardon. 2016. Families and Mobile Devices in Museums: Designing for Integrated Experiences. Fournal on Computing and Cultural Heritage 9, 2 (May 2016), 1-13. https://doi.org/10.1145/2891416

[63] Chiara Rossitto, Louise Barkhuus, and Arvid Engström. 2016. Interweaving place and story in a location-based audio drama. Personal and Ubiquitous Computing 20,2 (2016), 245-260.

[64] James A Russell. 1980. A circumplex model of affect. Journal of personality and social psychology 39, 6 (1980), 1161.

[65] D Sandlin. 2019. The backwards brain bicycle: Un-doing understanding

[66] Thecla Schiphorst. 2007. Really, Really Small: The Palpability of the Invisible. In Proceedings of the 6th ACM SIGCHI Conference on Creativity \& Cognition (Washington, DC, USA) (C\&C '07). Association for Computing Machinery, New York, NY, USA, 7-16. https://doi.org/10.1145/1254960.1254962

[67] Thecla Schiphorst. 2009. Soft(n): Toward a Somaesthetics of Touch. In CHI '09 Extended Abstracts on Human Factors in Computing Systems (Boston, MA, USA) (CHI EA '09). Association for Computing Machinery, New York, NY, USA, 2427-2438. https://doi.org/10.1145/1520340.1520345

[68] Kjeld Schmidt. 2008. Taking CSCW Seriously: Supporting Articulation Work (1992). In Cooperative Work and Coordinative Practices. Springer, 45-71.

[69] Phoebe Sengers and Bill Gaver. 2006. Staying Open to Interpretation: Engaging Multiple Meanings in Design and Evaluation. In Proceedings of the 6th Conference on Designing Interactive Systems (University Park, PA, USA) (DIS '06). Association for Computing Machinery, New York, NY, USA, 99-108. https://doi.org/10.1145/ 1142405.1142422

[70] V. Shklovskii. 2019. Art as Technique.

[71] Richard Shusterman. [n.d.]. The Encyclopedia of Human Computer Interaction.

[72] Richard Shusterman. 2008. Body Consciousness: A Philosophy of Mindfulness and Somaesthetics. Cambridge University Press.

[73] Richard Shusterman. 2012. Thinking through the Body: Essays in Somaesthetics. Cambridge University Press, Cambridge. https://doi.org/10.1017/ CBO9781139094030

[74] Richard Shusterman. 2016. Art of Eating. Body aesthetics (2016), 261.

[75] Anna Ståhl, Kristina Höök, and Jonas Löwgren. 2014. Evocative balance: Designing for interactional empowerment. International fournal of Design; 18 (2014).

[76] Anna Ståhl, Martin Jonsson, Johanna Mercurio, Anna Karlsson, Kristina Höök, and Eva-Carin Banka Johnson. 2016. The soma mat and breathing light. In Proceedings of the 2016 CHI Conference Extended Abstracts on Human Factors in Computing Systems. 305-308. 
[77] Anselm Strauss. 1985. Work and the division of labor. Sociological quarterly 26, 1 (1985), 1-19.

[78] Anna Ståhl, Martin Jonsson, Johanna Mercurio, Anna Karlsson, Kristina Höök, and Eva-Carin Banka Johnson. 2016. The Soma Mat and Breathing Light. In Proceedings of the 2016 CHI Conference Extended Abstracts on Human Factors in Computing Systems - CHI EA '16. ACM Press, New York, New York, USA, 305-308. https://doi.org/10.1145/2851581.2889464

[79] Dag Svanaes and Martin Solheim. 2016. Wag Your Tail and Flap Your Ears: The Kinesthetic User Experience of Extending Your Body. In Proceedings of the 2016 CHI Conference Extended Abstracts on Human Factors in Computing Systems (San Jose, California, USA) (CHI EA '16). Association for Computing Machinery, New York, NY, USA, 3778-3779. https://doi.org/10.1145/2851581.2890268

[80] Paul Tennent, Joe Marshall, Vasiliki Tsaknaki, Charles Windlin, Miquel Alfaras, and Kristina Höök. 2020. Soma Design and Sensory Misalignment. (2020), 12.

[81] Paul Tennent, Joe Marshall, Brendan Walker, Patrick Brundell, and Steve Benford. 2017. The challenges of visual-kinaesthetic experience. In Proceedings of the 2017 conference on designing interactive systems. 1265-1276.

[82] Vasiliki Tsaknaki and Ludvig Elblaus. 2019. A Wearable Nebula Material Investigations of Implicit Interaction. In Proceedings of the Thirteenth International Conference on Tangible, Embedded, and Embodied Interaction (Tempe, Arizona, USA) (TEI '19). Association for Computing Machinery, New York, NY, USA, 625-633. https://doi.org/10.1145/3294109.3295623

[83] Muhammad Umair, Corina Sas, and Muhammad Hamza Latif. 2019. Towards Affective Chronometry: Exploring Smart Materials and Actuators for Real-Time Representations of Changes in Arousal. In Proceedings of the 2019 on Designing Interactive Systems Conference (San Diego, CA, USA) (DIS '19). Association for Computing Machinery, New York, NY, USA, 1479-1494. https://doi.org/10.1145/ 3322276.3322367

[84] Raphael Velt, Steve Benford, and Stuart Reeves. 2017. A Survey of the Trajectories Conceptual Framework: Investigating Theory Use in HCI. In Proceedings of the
2017 CHI Conference on Human Factors in Computing Systems. ACM, Denver Colorado USA, 2091-2105. https://doi.org/10.1145/3025453.3026022

[85] Raphael Velt, Steve Benford, and Stuart Reeves. 2017. A survey of the trajectories conceptual framework: Investigating theory use in HCI. In Proceedings of the 2017 CHI conference on human factors in computing systems. 2091-2105.

[86] Richard Wetzel, Tom Rodden, and Steve Benford. 2017. Developing ideation cards for mixed reality game design. Transactions of the Digital Games Research Association 3, 2 (2017).

[87] Danielle Wilde. 2012. HipDisk: Understanding the Value of Ungainly, Embodied, Performative, Fun. In CHI '12 Extended Abstracts on Human Factors in Computing Systems (Austin, Texas, USA) (CHIEA '12). Association for Computing Machinery, New York, NY, USA, 111-120. https://doi.org/10.1145/2212776.2212789

[88] Danielle Wilde, Anna Vallgårda, and Oscar Tomico. 2017. Embodied Design Ideation Methods: Analysing the Power of Estrangement. In Proceedings of the 2017 CHI Conference on Human Factors in Computing Systems (Denver, Colorado, USA) (CHI '17). Association for Computing Machinery, New York, NY, USA, 5158-5170. https://doi.org/10.1145/3025453.3025873

[89] Danielle Wilde, Anna Vallgårda, and Oscar Tomico. 2017. Embodied Design Ideation Methods: Analysing the Power of Estrangement. In Proceedings of the 2017 CHI Conference on Human Factors in Computing Systems - CHI '17. ACM Press, Denver, Colorado, USA, 5158-5170. https://doi.org/10.1145/3025453.3025873

[90] Charles Windlin. 2020. Designing with the Body: Addressing Emotion Regulation and Expression. In Companion Publication of the 2020 ACM Designing Interactive Systems Conference (Eindhoven, Netherlands) (DIS' 20 Companion). Association for Computing Machinery, New York, NY, USA, 557-562. https://doi.org/10. 1145/3393914.3395835

[91] Charles Windlin, Anna Ståhl, Pedro Sanches, Vasiliki Tsaknaki, Pavel Karpashevich, Madeline Balaam, and Kristina Höök. 2019. Soma Bits: Mediating technology to orchestrate bodily experiences. Figshare (2019). https://doi.org/10.6084/m9. figshare.7855799.v2 